\title{
Physician Willingness and Resources to Serve More Medicaid Patients: Perspectives from Primary Care Physicians
}

\author{
Anna S. Sommers, ${ }^{1}$ Julia Paradise, ${ }^{2}$ and Carolyn Miller ${ }^{3}$ \\ ${ }^{1}$ Center for Studying Health System Change \\ ${ }^{2}$ Kaiser Commission on Medicaid and the Uninsured \\ ${ }^{3}$ Independent Consultant
}

\section{Supplement}

doi: http://dx.doi.org/10.5600/mmrr.001.02.s01

Appendix Table 1. Primary Care Physician' Acceptance of New Patients by Physician's Level of Medicaid Participation 
Appendix Table 2. Primary Care Physician' ${ }^{1}$ Practice Revenue from Medicare and Medicaid

by Physician's Level of Medicaid Participation, 2008

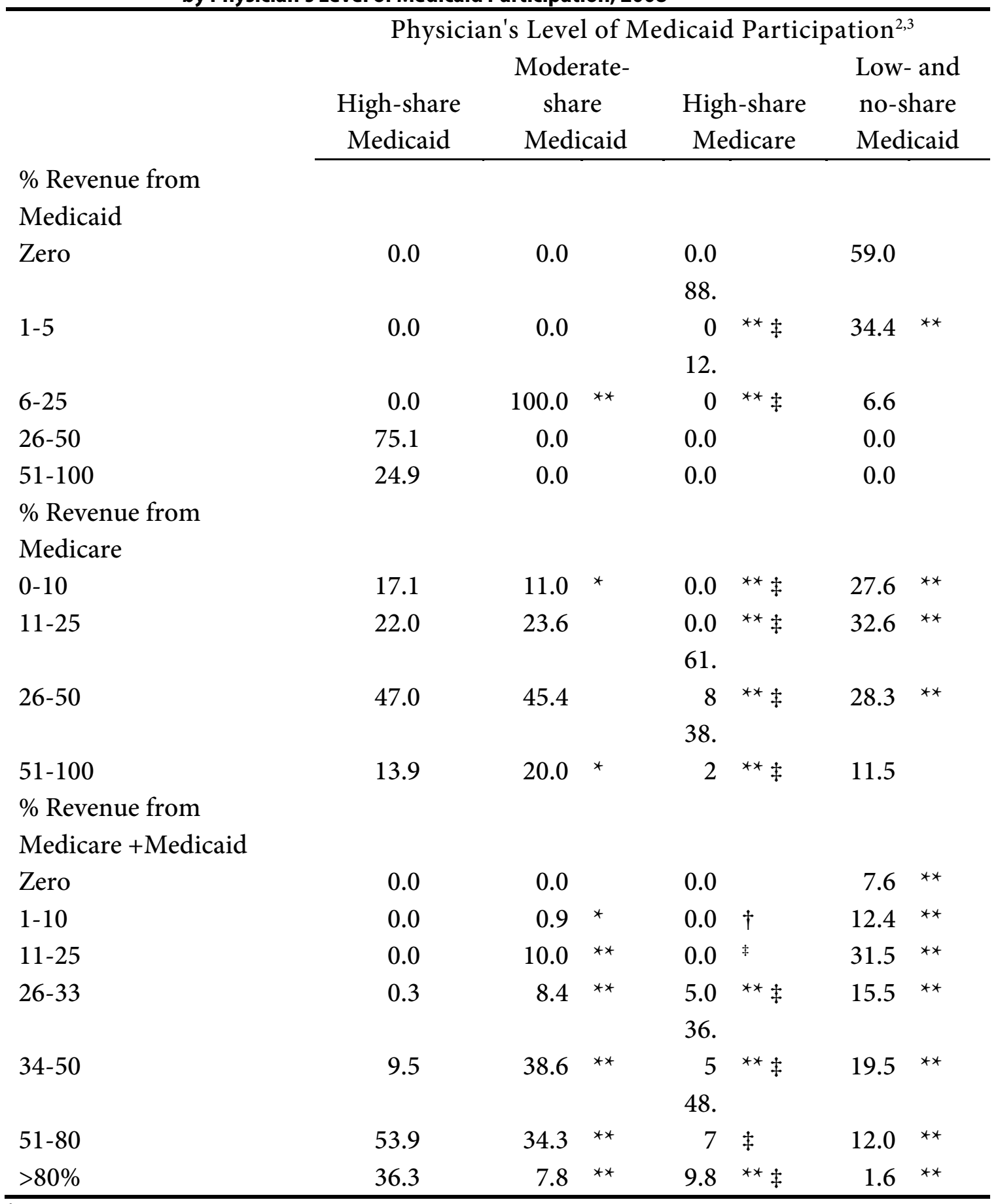

${ }^{1}$ Sample excludes pediatricians and physicians working most hours on hospital staff or in emergency room.

${ }^{2}$ Asterisks $\left({ }^{*}\right)$ denote a difference from high-share Medicaid physicians statistically significant at ${ }^{*} \mathrm{p}<.05$ and ${ }^{* *} \mathrm{p}<.01$.

${ }^{3} \dagger$ denotes a difference between moderate-share Medicaid and high-share Medicare physicians statistically significant at $\dagger \mathrm{p}<.05$ and $\ddagger \mathrm{p}<.01$.

Source: 2008 HSC Health Tracking Physician Survey 


\section{Medicare \& Medicaid Research Review}

2011

Volume 1, Number 2

\section{Mission Statement}

Medicare \& Medicaid Research Review is a peer-reviewed, online journal reporting data and research that informs current and future directions of the Medicare, Medicaid, and Children's Health Insurance programs. The journal seeks to examine and evaluate health care coverage, quality and access to care for beneficiaries, and payment for health services.

http://www.cms.gov/MMRR/

\section{U.S. Department of Health \& Human Services}

Kathleen Sebelius,

Secretary

Centers for Medicare \& Medicaid Services

Donald M. Berwick, M.D.

Administrator

Center for Strategic Planning

Anthony D. Rodgers,

Deputy Administrator and Director

Editor-in-Chief David M. Bott, Ph.D.

Senior Editor Cynthia Riegler, M.A.

\section{Editorial Board}

Gerald S. Adler, M.Phil., CMS/Center for Strategic Planning

William J. Buczko, Ph.D., CMS/Innovation Center

Todd Caldis, Ph.D., J.D., CMS/Office of the Actuary

Craig F. Caplan, M.A., CMS/ Innovation Center

Jesse M. Levy, Ph.D.,

CMS/ Innovation Center
Melissa A. Evans, Ph.D., CMS/Center for Medicare

Isidor R. Strauss, F.S.A., CMS/Office of the Actuary

Fred G. Thomas, Ph.D., C.P.A., CMS/ Innovation Center

Robert Weech-Maldonado, Ph.D., University of Alabama, Birmingham

Submission Guidelines: www.cms.gov/MMRR/InformationforAuthors

Contact:mmrr-editors@cms.hhs.gov

(c) 2011 Centers for Medicare \& Medicaid Services

All material in the Medicare \& Medicaid Research Review is in the public domain and may be duplicated without permission. Citation to source is requested. 